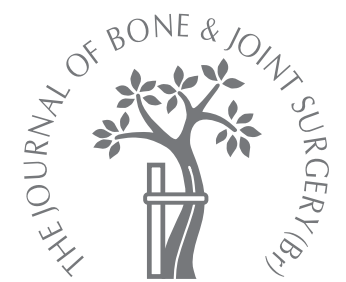

- CASE REPORT

\title{
Injury to the axillary artery, a complication of fixation using a locking plate
}

\begin{abstract}
A. Khunda,
A. N. Stirrat,

P. Dunlop
\end{abstract}

From Sunderland

Royal Hospital,

Sunderland, England

A. Khunda, MBChB, Senior House Officer in Trauma \& Orthopaedics

James Cook University Hospital, Marton Road, Middlesbrough TS4 3BW, UK.

A. N. Stirrat, $\operatorname{FRCS}(\mathrm{Ed})$ Consultant Orthopaedic Surgeon

P. Dunlop, MD, FRCS, Consultant Vascular Surgeon Sunderland Royal Hospital, Kayll Road, Sunderland SR4 7TP, UK.

Correspondence should be sent to $\operatorname{Dr}$ A. Khunda; e-mail: aimankhunda@yahoo.co.uk

(C2007 British Editorial Society of Bone and Joint Surgery doi:10.1302/0301-620X.89B11. $19264 \$ 2.00$

$J$ Bone Joint Surg [Br] 2007;89-B:1519-21.

Received 2 February 2007;

Accepted 17 May 2007

\begin{abstract}
The proximal humerus internal locking system is an internal fixation device consisting of a low-profile plate and locking screws, which is used for the fixation of three- and four-part fractures of the proximal humerus. We describe a case in which the screws cut out of the humeral head causing injury to the axillary artery necessitating urgent removal of the implant.
\end{abstract}

Fractures of the proximal humerus are common among the elderly with osteoporosis. ${ }^{1}$ Management of three- and four-part fractures remains controversial because of the disappointing results from all methods of treatment. ${ }^{2-6}$ Previously used devices for internal fixation have been rudimentary and prone to failure, even leading to migration of metal with consequent complications. ${ }^{7-9}$ The proximal humerus internal locking system (Philos; Synthes Limited, Hertfordshire, England) consists of a low-profile plate with proximal locking screws which has allowed the fixation of fractures that were previously considered to be inoperable or suitable only for hemiarthroplasty. ${ }^{10}$ We describe a case which demonstrates the potentialy serious consequences of the device cutting out of the humeral head.

\section{Case report}

A 67-year-old woman presented with a widely displaced fracture of the left humeral neck following a fall (Fig. 1). There was no neurological deficit and the radial pulse was preserved. Internal fixation was performed the following day, using a short Philos plate held by six proximal and three distal locking screws (Fig. 2). A collar-and-cuff sling was applied and assisted movement under supervision of a physiotherapist was allowed, but patient compliance was limited. A radiograph taken 12 days after the operation showed that the screws had cut out from the humeral head allowing displacement of the plate which remained attached to the humeral shaft (Fig. 3). It was decided to undertake a revision procedure using a hemiarthroplasty. There was a tense haematoma in the deltopectoral interval and around the displaced implant. After removal of the proximal locking screws and plate there was considerable deep haemorrhage. Control of the axillary artery was achieved with vascular clamps on either side of a tear in the artery $0.5 \mathrm{~cm}$ long. This was repaired with a running suture of 5/0 nylon. A cemented hemiarthroplasty was then introduced. When the clamps were released there was further bleeding from another, more distal perforation in the axillary artery. This was also repaired. During this operation she received six units of blood and four units of fresh-frozen plasma.

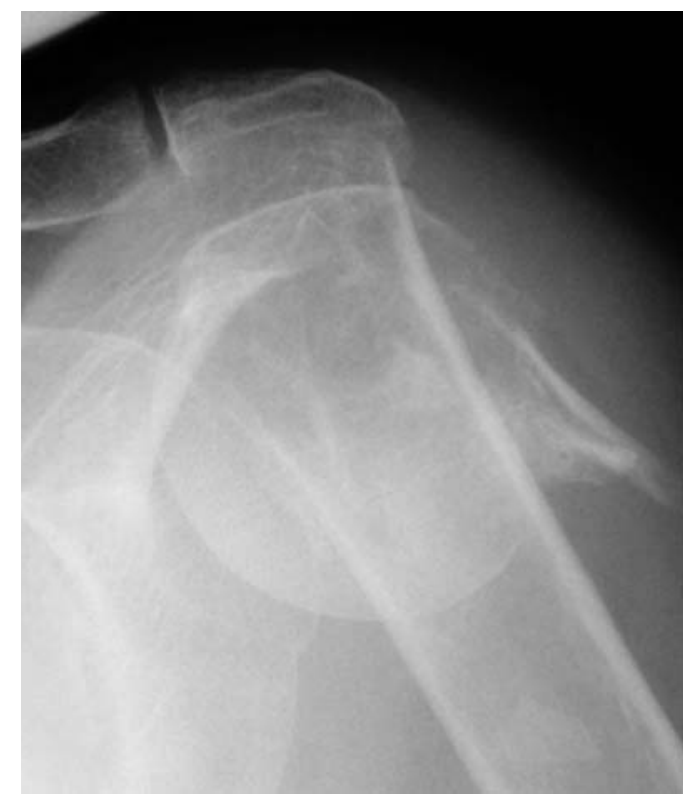

Fig. 1

Anteroposterior radiograph showing the fracture at presentation. 


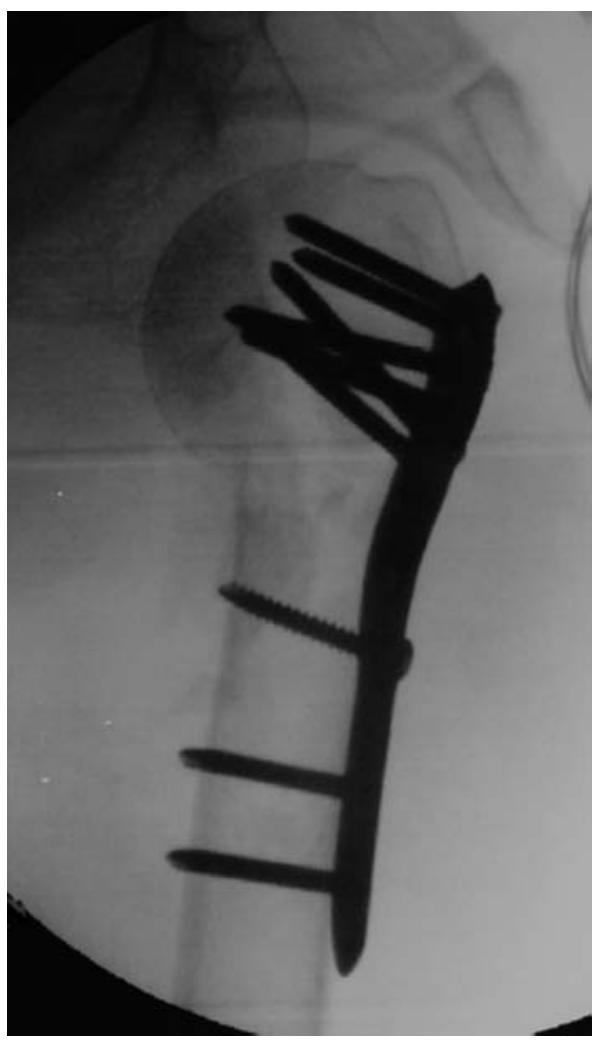

Fig. 2

Anteroposterior radiograph showing the Philos plate in position.

Throughout the following evening, the swelling around the left shoulder continued to increase. Pain and tachycardia indicated continuing haemorrhage and she was therefore taken back to theatre where a vascular surgeon explored the axillary artery and placed additional sutures at one of the previous sites of repair. Further transfusion was necessary with ten units of blood and eight units of fresh-frozen plasma. After 36 hours in intensive care, she was transferred to the orthopaedic ward. At that stage, the left arm was well perfused and there was no neurological deficit. A tense haematoma, developing on the left anterior chest wall, was investigated by aortic-arch angiography. There was no evidence of a false aneurysm or arterial narrowing (Fig. 4). She was discharged from hospital 20 days after the last exploration. At outpatient review five weeks later, the hemiarthroplasty was found to have dislocated anteriorly resulting in poor function, but only minimal discomfort. She elected to have no further surgery.

\section{Discussion}

Vascular injury related to surgery for fractures of the proximal humerus is rare. A false aneurysm of the axillary artery has been reported after intramedullary nailing of a fracture of the proximal humerus locked by a long proximal

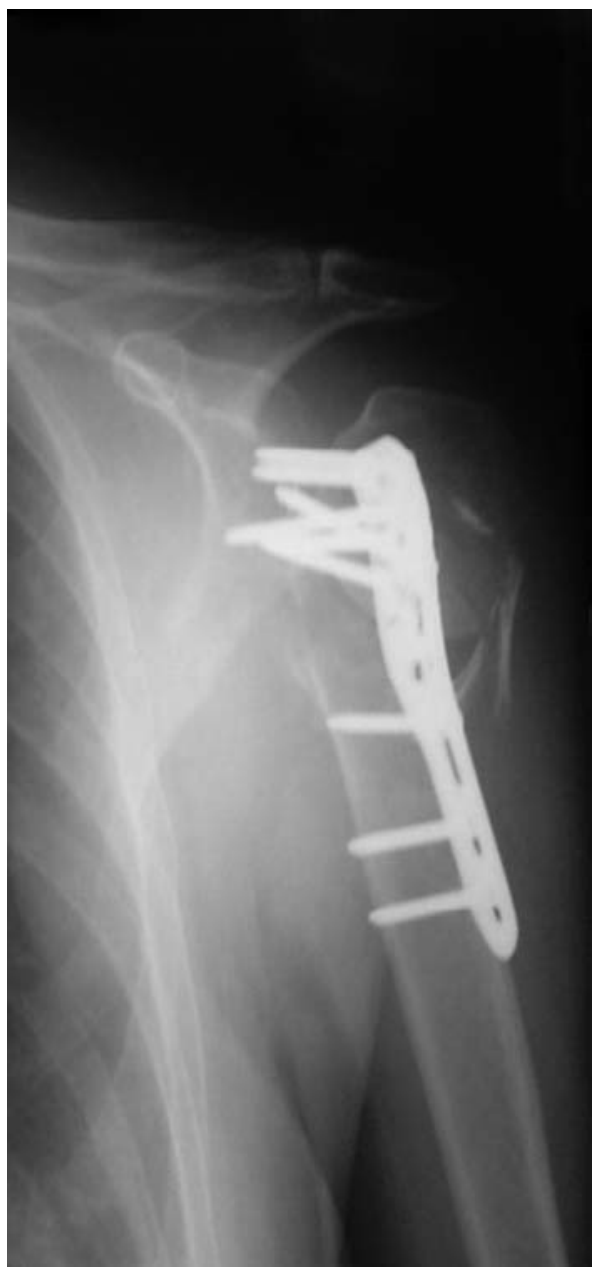

Fig. 3

Posteroanterior radiograph of the chest showing migration of the implant into the axilla.

screw. ${ }^{11}$ The propensity for metal placed in the shoulder to migrate is well recognised. ${ }^{7-9}$ Wires have been known to enter the thoracic cavity and to be located in the heart. ${ }^{7}$

The fixation of complex proximal humeral fractures may be difficult because of the quality of bone and the shortcomings of the implants that are available. The Philos system, by virtue of the divergent locking screws, offers increased security of fixation particularly in the presence of osteoporosis. The technique is critical and requires reduction of the fracture before any screws are inserted, placement of the plate at an appropriate level in order to avoid subacromial impingement and to allow for optimal placement and purchase of screws in the cancellous bone of the humeral head which is the weak point of the fixation. Secure fixation allows early movement and return of function.

In this case, screws probably of inadequate length, cut out of the osteoporotic humerus so that the screws could migrate medially towards the neurovascular bundle (Fig. 3). 


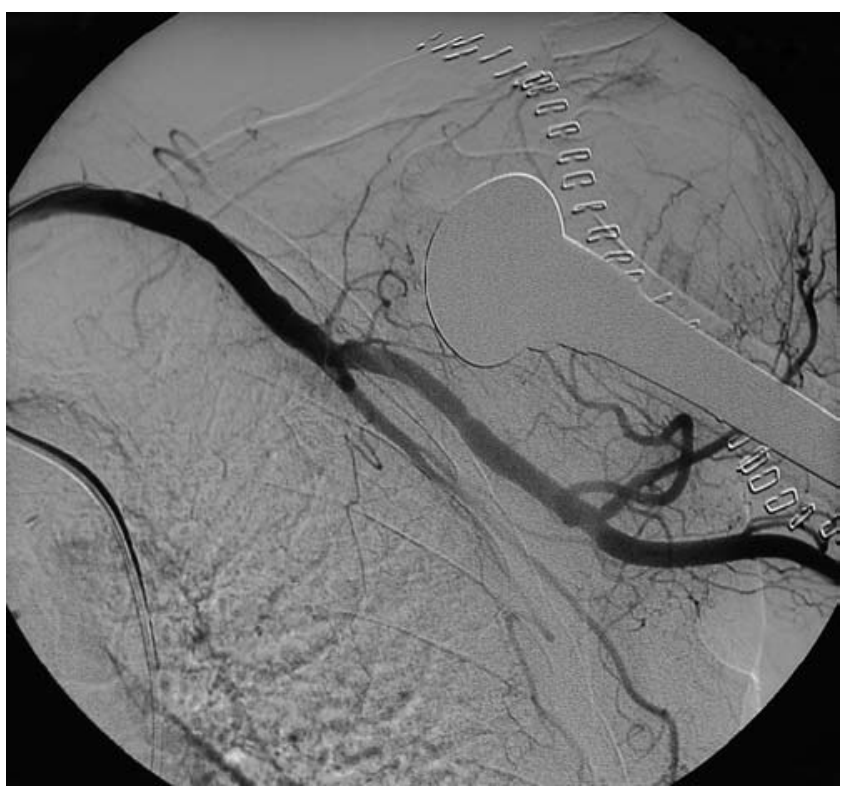

Fig. 4

Angiography after the hemiarthroplasty showing no evidence of aneurysm or narrowing of the axillary artery.

The minor lacerations in the axillary artery were consistent with perforation by the sharp tips of the screws. Control of bleeding proved to be difficult and continued even after the second attempt with the development of a haematoma in the chest wall. Angiography showed no evidence of a false aneurysm or communication with the axillary artery. Subsequent anterior dislocation of the hemiarthroplasty was attributable to failure of the repair of the tuberosities. At the present time, 12 months after the initial procedure, the pain is tolerable and further surgery is not under consideration.

When using such devices for internal fixation of this fracture, the surgical technique has to be meticulous to achieve reduction and to ensure that the hold of the screws in bone is secure.

No benefits in any form have been received or will be received from a commercial party related directly or indirectly to the subject of this article.

\section{References}

1. Hessmann MH, Blum J, Hofmann A, Küchle R, Rommens PM. Internal fixation of proximal humeral fractures. Eur J Trauma 2003;29:253-61.

2. Robinson CM, Page RS, Hill RMF, et al. Primary hemiarthroplasty for treatment of proximal humeral fractures. J Bone Joint Surg [Am] 2003;85-A:1215-23.

3. van den Broek CM, van den Besselaar M, Coenen JM, Vegt PA. Displaced proximal humeral fractures: intramedullary nailing versus conservative treatment. Arch Orthop Trauma Surg 2007;127:459-63.

4. Bernard J, Charalambides C, Aderinto J, Mok D. Early failure of intramedullary nailing for proximal humeral fractures. Injury 2000;31:789-92.

5. Zyto K, Ahrengart L, Sperber A, Tornkvist H. Treatment of displaced proximal humeral fractures in elderly patients. J Bone Joint Surg [Br] 1997;79-B:412-17.

6. Nanda R, Rangan A, Al Maiya M, Goodchild L, Finn P, Gregg PJ. Conservative management of proximal humeral fractures: functional scores outcome at one year. J Bone Joint Surg [Br] 2006;88-B(Supp 1):140.

7. Lyons FA, Rockwood CA Jr. Migration of pins used in operation on the shoulder. J Bone Joint Surg [Am] 1990;72-A:1262-7.

8. Norrell H Jr, Lewellyn RC. Migration of a threaded Steinman pin from an acromioclavicular joint into the spinal canal: a case report. J Bone Joint Surg [Am] 1965;47-A:1024-6.

9. Lindsey RW, Gutowski WT. The migration of a broken pin following fixation of the acromioclavicular joint: a case report and review of the literature. Orthopedics 1986;9:413-16.

10. Vallier HA. Treatment of proximal humerus fractures. J Orthop Trauma 2007;21:469-76.

11. Safar HA, Farid E, Nakhi H, Asfar S. Vascular injuries caused by orthopaedic screws: a case report. Med Princ Pract 2004;13:230-3. 